\title{
CARACTERÍSTICAS FORMALES Y MODALIDADES DE LA POESÍA EN PROSA
}

\author{
Benigno LEÓN FELIPE \\ Universidad de La Laguna
}

El primer problema que plantea la aparición de un nuevo género literario es su caracterización como tal y las relaciones que se establecen con los demás géneros. En el caso concreto del poema en prosa confluyen una serie de circunstancias que complican sobremanera todo intento de delimitación genérica. Por un lado, y aunque el siglo y medio de existencia le otorga un cierto abolengo, el poema en prosa es una manifestación literaria que se sigue percibiendo como algo muy reciente e indefinido, no es visto como un género totalmente "hecho" y con una naturaleza específica. Su cultivo, además, suele ser ocasional -no existen poetas exclusivos de poesía en prosa-, se omiten en la mayoría de las antologias poéticas, y escasean los estudios generales.

Por otro lado, uno de los rasgos característicos del poema en prosa es su formu bastante libre $y$, por tanto, poco propicia para ser encorsetado en estructuras fijas. Mary Ann Caws (1983a: 180) dice al respecto que la estructura final del poema en prosa tiene una especial importancia, pues actúa de forma retrospectiva para construir o destruir lo que ya ha sido previamente destruido.

El problema de este "monstruo oximorónico", como lo denomina Michel Beaujour (1983: 50), no es el de su existencia, pues los textos pueden describirse individualmente sin mayores problemas, but the genre, type, sort of "speech act", kind of discurse, what have you, is so elusive that the theoretician may well wish to decide that there is after all no such thing as a prose poem, since this notion cannot be construed as the objet of a poetic enquiry. ${ }^{1}$ (Beaujour, ibid.: 40 )

No puede negarse su existencia, como tampoco puede negarse su naturaleza y condición muy complejas. Por tanto, conviene abordar el problema de la definición del poema en prosa aceptando de antemano los inconvenientes y dificultades propios de un género al que, como a otros géneros poéticos, no se le puede aplicar el criterio de "máxima pureza", y que, siempre, por más que acotemos el espacio en el que se mueve, habrá textos fronterizos ante los que sólo valdrá la adjudicación genérica personal que haga el lector o crítico.

1 "pero el género, la clase de "acto de habla", el tipo de discurso, lo que se tenga, es tan escurridizo que el teórico bien podria decidir que no existe tal poema en prosa, pues no es una noción que pueda constitujr el objotivo de un estudio poético". 
El primer aspecto que hemos de señalar afecta a su consideración general: el poema en prosa en un género, o subgénero, literario autónomo $y$ diferente. No es un hibrido ni una forma intermedia entre la prosa y el verso, sino "un genre distinct" (Bernard, 1959: 434). Esta idea defendida por Bernard es esencial, pues signilica que hemos de darle al poema en prosa el mismo tratamiento genérico que al poema en verso. El poema en prosa hemos de analizarlo, por tanto, desde una perspectiva lírica, no narrativa. La poesia se puede manifestar mediante formas métricas: poesía en verso; o mediante formas no métricas: poesia en prosa. Las diferencias fundamentales entre ambas modalidades poéticas son las inherentes a estos dos sistemas de expresión.

\section{PROSA Y VERSO.}

La aparente contradicción del oxímoron de la expresión "poesía en prosa" es una reminiscencia de las poéticas clásicas en las que poesía y verso suelen identificarse. Este carácter contradictorio ha marcado en gran medida los intentos de definición y caracterización del nuevo género. Son varios los estudios que inciden en esta cuestión. Suzanne Bernard (1959: 434) habla de dos "polos" -organización artística y anarquia destructivaque, a su vez, son la consecuencia del doble principio que caracteriza al poema en prosa, pues "toma prestados sus elementos de la prosa", pero "se construye como un poema". En palabras de Bernard: nous allons voir que tout l'ensemble complexe de lois qui président à l'organtsation de ce genre original se trouve déjá en germe, en puissance, dans sa seule dénomination: poème en prose. (...): et en effet le poème en prose, non seulement dans sa forme, mais dans son essence, est fondé sur l'union des contraires: prose et poésie. liberté et rigueur, anarchie destructice et art organisateur. ${ }^{2}$

Tzvetan Todorov (1983: 61) le objeta la inconsistencia del argumento principal de la afirmación anterior: $/$ t is one thing to state that another thing to say that it can sometimes be governed by one principle and sometimes by opposite for instance, eilher by a tendency to order or by a tendency lo disorder). ${ }^{3}$

De la primera afirmación añade que puede confirmarse o invalidarse estudiando ejemplos, pero de la segunda dice que carece de contenido,

2 "vanos a ver que la totalidad del conjunto de leyes que rigen la organización de este original género se encuentra ya potencialmente contenida en su propío título: poema en prosa. [... I: y en efecto el poema en prosa, no solamente en su forma, sino en su esencia, está fundado en le unión de contrarios: prosa y poesía, libertad y rigor. anarquia destructora y arte organizador".

${ }^{3}$ Cito de la traducción inglesa hecha por Barbara Johnson, recogida en Mary Ann Caws y Hermine Riffaterre (eds.), 1983: 60-78. "Una cosa es afirmar que este género se caracteriza por la unión de opuestos, pero es algo bien distinto decir que puede estar a veces regido por un único príncipio $y$ a veces por su opuesto (por ejemplo, por una tendencia al orden o por una tendencia el desorden)." 
porque "to say something that it is characterized either by $A$ or by not-A is to say nothing at all"4. Además, creemos, se le podría objetar tambièn que hasta qué punto puede hablarse de conceptos contrarios en la época en que surge el poema en prosa, si los antecedentes y la situación de la poesía en su momento nos indican que las fronteras ya no existen, $y$, aunque se mantienen las lógicas diferencias, la intención de los escritores se dirige precisamente a diluir estos términos contrapuestos. Como muy bien señala Ángel Crespo (1966: 229) "El problema fundamental de la poesía contemporánea no es el de la prosa y el verso, sino el de su forma de enfrentarse con el mundo".

Pero frente a esta tendencia general de eliminación de barreras entre contrarios, surgen los poemas en prosa de Baudelaire que reflejan, tanto en su composición general como en su estructura temática, un deseo consciente de potenciar conceptos opuestos. Siguiendo a Todorov (ibid.: 64), es "as though Baudelaire had only been attracted to the genre insifar as it enabled him to find an apropriale form (a "correspondance") for a thematics of duality, contrast and opposition. ${ }^{55}$ Los textos de Baudelaire encajan, por tanto, perfectamente en la delinición dada por Suzanne Bernard.

Pero lo que se propone Todorov en su artículo es tratar de definir la naturaleza de lo que denomina "poesía sin verso", y, por extensión, llegar al concepto de "lo poético", que lo circunscribe en la disyuntiva siguiente: "is there such a thing as a transcultural, transhistorical "poeticity", or can one only come up with local answers, clearly circumscribed in time and in space?" (ibid.: 60). El punto de partida lo sitúa en la tesis de Bernard, para quien lo poético se expresa en unas ocasiones mediante repeticiones, como es el caso de Baudelaire, y en otras mediante el rechazo de la representación a través de la negación del mundo real y de incoherencias o discontinuidad verbales, como en Rimbaud. Ambos procedimientos tienen como denominador común, y que es la esencia de la poeticidad según Bernard, la noción de atemporalidad, lo que llama "el eterno presente". Para Todorov (1983: 77) es una distorsión violenta reducir estos dos procedimientos a la simple atemporalidad, que es sólo una consecuencia secundaria tanto del rechazo de la representación en Rimbaud como del orden de correspondencias en Baudelaire. Todorov no responde a la pregunta que él mismo se plantea sobre la poeticidad, aunque deja entrever la posibilidad de la existencia, a absoluto".

4 "decir de algo que se caracteriza por $A$ o por no-A es no decir nada en

s "como si Baudelaire sólo se hubiese sentido atraído por el género en la medida en que le permitía encontrar una forma adecuada (una "correspondencia") para una temática de la dualidad, el contraste y la oposición".

6" "Lexiste algo parecido a una "poeticidad" transcultural y transhistórira, o podemos encontrar tan solo respuestas locales, claramente circunscritas en el espacio y en el timpo?" 
pesar de todo, de algunas afinidades que permitan hablar de un concepto invariable, en el tiempo y en el espacio, de poesia en verso o "sin verso".

Desde una perspectiva lingüística-estructural, y aunque el objeto de su estudio es el poema en verso, Jean Cohen (1974) nos ofrece una visión más equilibrada de la dicotomia verso-prosa. Parte Cohen (Ibíd: 11 y ss.) del principio de Martinet de la doble articulación del lenguaje y de la combinación que el escritor haga de los dos niveles -lónico y semántico- de procedimientos poéticos que se le ofrece, resulta la siguiente combinación:

$\quad$ género
poema en prosa
prosa versificada
poesía integral
prosa integral

fónicos
+
+
+
-

caracteres poéticos

El poema en prosa, que según Cohen también podria ser llamado "poema semántico", se caracterizaria, pues, por usar exclusivamente los procedimientos semánticos, elementos suficientes para crear poesía, aunque sea la versificación el instrumento más eficaz para lograrla. El verso es. sin lugar a dudas, el principal procedimiento de poetización.

Hermine Riffaterre (1983: 98-116) parte también de lo dicho por Suzanne Bernard, pero destacando como mérito de su enfoque crítico el intento de definir el poema en prosa como un texto cerrado, con un comienzo y un fin bien definidos, que lo convierten en un todo organizado. Cree, como Bernard, que la ruptura original con el verso sigute siendo el principio activo del género, esencial para su definición, pero también para que el lector pueda percibirlo. Y es precisamente en la experiencia de la lectura donde $\mathrm{H}$. Riffaterre propone buscar las claves de la interpretación poética del género. El elemento que hace que el lector perciba la prosa de un poema como algo distinto de la simple prosa es la repetición de constantes de todo tipo: reiteraciones léxicas, anáforas, paralelismos, referencias intertextuales, etc. Coincide en este punto $H$. Riffaterre con Lázaro Carreter al situar el fenómeno de la repetición en el centro de la cuestión, aunque Lázaro (1979: 60), en principio, como hemos apuntado más arriba, lo aplica exclusivamente al verso libre: "la repetición está en la entraña misma del verso libre, como su fundamental principio constituti$v 0^{\prime}$. Cabe preguntarse si esta aseveración de Lázaro es aplicable también a la prosa. Es decir, si el poeta de poemas en prosa, lo mismo que el poeta de verso libre, se ve obligado a usar todo tipo de recurrencias -fónicas, morfológicas, léxicas y sintácticas- para neutralizar la tendencia de la prosa a ser prosa común, "al vedarse voluntariamente el poeta los instrumentos rítmicos lijos que el verso tradicional le proporciona", y, por tanto, "al imponerse programáticamente como sistema la misma libertad en la elección del grupo fónico que la permitida al habla común." (Lázaro Carreter, ibid.: 60) 
Pero de H. Riffaterre nos resulta más interesante la conclusión final en la que propone en qué radica la distinción entre ambas formas de expresión. pero desde la perspectiva del lector que percibe la unidad formal del poema en prosa como si tuviese forma métrica. La diferencia entre el poema en prosa y el poema en verso is that in the latter the formal framework has permanent characteristics peculiar to all its meanings, to all the texts the author wishes to insert. in the prose poem, on the contrary. the formal frameworks is ad hoc, built out of the content put into it and coextensive with it. just as the content is coextensive with the verse in the verse poem. It is the ad hoc constant that replaces versificacion. ${ }^{7}$

La diferencia se centra, pues, en que la determinación de la forma de expresion se produce en el mismo momento en que se elabora el texto, y condicionada por el desarrollo del significado; no viene impuesta por el carácter tradicional de la versilicación.

Esta postura es muy similar a la que mantiene Michael Riffaterre (1983: 117-132), para quien también el factor unificador de la prosa poética ha de ser generado por el propio texto. El elemento que desempeña esta función unificadora es la significación, y que él propone "to find the latter in a constand invariant relationship between text and intertex, in an invariable intertextuality"

Si el marco formal del poema en prosa no existe a priori, sino que se configura en el momento de su elaboración y dependiendo del contenido, cabría preguntarse si este planteamiento no nos llevaria a entender el poema en prosa como un género en el que el grado de diversidad formal. consecuencia de la disparidad de contenidos que puede albergar, es tan grande que no seria posible hablar de constantes formales que sirvan de referencia genérica, sobre todo, para los lectores. Cualquier intento taxonómico al respecto estaría, entonces, abocado a una pura casuística sin sentido.

El poema en prosa queda situado, genéricamente, entre el cuento y la poesía versolibrista. Comparte con ellos la brevedad, la unidad orgánica y la condensación expresiva, pero, desde una perspectiva textual, resulta imposible trazar una frontera entre ellos, sobre todo entre el cuento lírico y el poema en prosa. Con la poesía versolibrista nos queda siempre el recurso de la disposición tipogräfica como elemento diferenciador incuestionable, ya que desde el punto de vista constitutivo las formas de expresión

7 "estriba en que en el segundo el marco formal tiene características permanentes peculiares a todos sus signifjcados, a todos los textos que el autor desea insertar. En cambio, en el poema en prosa, el marco formal es ad hoc, construido a partir de su contenido y coextenso con al, del mismo modo que el contenido es coextenso con el verso en el poema en verso. Es la constanto ad hoc lo que sustituye a la versificación.

"encontrarla en una relación invariante constante entre texto e intertexto, en una intertextualidad invariable". 
del poema en prosa y del poema versolibrista no presentan rasgos diferenciales.

Podria parecer que hay una cierta contradicción en lo dicho anteriormente, es decir, entre la afirmación de que el poema en prosa en un género diferente y que, al mismo tiempo, no es posible fijar claramente sus límites. Si es diferente deberia poder delimitarse perfectamente. Creo que el problema se resuelve si aceptamos que el poema en prosa no se materializa en una única forma, sino que existen, como en la poesía en verso, diversos tipos, y que de algunos de ellos podría pasarse, sin solución de continuidad, a los géneros colaterales, como el cuento lírico y la poesia versolibrista en versículo extralargo, e incluso, a otros textos, como a algunos tipos de ensayo creativo.

El origen del poema en prosa nos aporta algunas consideraciones que deben ser tenidas en cuenta. Por un lado podemos constatar que desde su génesis este género está intimamente vinculado al ámbito urbano. Baudelaire (1954) ya lo había dicho en sus Pequeños poemas en prosa: la poesia moderna, y el poema en prosa es su principal manifestación, surge de la "frecuentación de las grandes ciudades". Y, por otro, la gran influencia que las artes visuales, también desde sus origenes, han ejercido sobre el nuevo género. Del primer hecho se mantiene la tendencia del poema en prosa a las referencias temáticas urbanas, y del segundo el gusto de los cultivadores del género por las descripciones impresionistas siguiendo técnicas pictóricas. Ahora bien, conviene también señalar que, a pesar del contexto urbano en que suele moverse, y a la tendencia a incorporar elementos narrativos y descriptivos en mayor proporción que la poesía en verso, al poema en prosa no se le puede imponer más limitaciones temáticas que las derivadas de su condición poética. En todo caso, el carácter poético le viene dado por el tratamiento o la particular visión que el autor le dé, no por la cantidad de narración o descripción que un poema, en verso o prosa, pueda soportar.

\section{CARACTERISTICAS FORMALES}

Es evidente que si existen textos que, al menos tácitamente, se clasifican como poemas en prosa, debe inferirse que poseen algunas características formales comunes. Como señala Suzanne Bernard (1959: 13), el poema en prosa posee un principio anárquico y destructor de las leyes habituales de la poesía, pero se ve muy pronto obligado, si quiere convertirse en un género viable, a reemplazar esas leyes por otras. Por tanto, es una exigencia de la poesia como género crear una nueva forma que sustituya a la anterior y sirva de referencia y modelo. La repetición de una serie de constantes es lo que hace que el lector posea los elementos de referencia suficientes para descifrar y catalogar un texto como perteneciente a una clase determinada.

Los aspectos sobre los que ha habido más acuerdo, en principio, son los relativos a la extensión y unidad de sentido, aplicándose al poema en prosa las mismas constantes que al poema en verso, es decir, el poema lírico debe ser, por naturaleza, breve y autónomo. Según John Simon (1965: 664), la 
longitud del poema en prosa, por lo general, oscila entre media y tres o cuatro páginas, que es el término medio de un poema lírico normal. Esta extensión viene exigida por la intensidad que se le supone al poema, pues, como añade J. Simon; "if it is any longer, the tensions and impact are forfeited, and it becomes-more or less poetic-prose"y. Un texto en prosa será un poema sólo si tiene un principio y un final perfectamente delinidos. Es precisamente esta noción de unidad lo que distinguiria a un poema en prosa de la prosa poética fragmentaria que puede ocasionalmente encontrarse en una novela, un cuento o un ensayo.

Para Suzanne Bernard (1959: 15), la brevedad es también una de las condiciones básicas que debe poseer el poema en prosa: Les deux conditions dont je viens de parler, unité y gratuité, nous conduisent à une troisième, plus particulière au poème en prose, et qui est la brièveté. Plus que le poème en vers, le poème en prose doit éviter les digressions morales ou autres, les développements explicatif-tout ce qui le raménerait aux autres genres de la prose, tout ce qui nuirait à son unité, à sa densité-, Precisément parce que sa force poétique ne vient pas d'une incantation mesurée. mais d'une synthèse illuminatrice, on peut lui appliquer dans toute sa rigueur la fameuse déclarations de Poe: "Un long poèmen'existe pas; ce qu'on entend par un long poème est une parfaite contradiction de termes". On a souvent remarqué, et on peut poser en principe, que le poème en prose moderne est toujours bref. ${ }^{\text {to }}$

Y también Luis Cernuda (1971: 259) participa claramente de esta opinión cuando afirma que "si la longitud mayor o menor del poema en verso es cuestión controvertible, no parece serlo la de la brevedad del poema en prosa".

Esta idea de identificar lo poético con lo breve se apoya en la creencia de que "sreal poetry" intrinsically is a discharge of short duration. In some cases (imagism. Reverdy's works, surrealism) poetry becomes largely synonymous with images understood to be vehicles of analogical revelation occurring in a flash. "11 (Michel Beaujour, 1983: 42).

" "si as más largo, las tensiones y ol impacto se pierden y se convierte en prosa -más o menos poética-".

10 "Las dos condiciones que acabo de subrayar, unidad y gratuidad, nos llevan a una tercera, más particular al poema en prosa, es la brevedad. Más que el poema en verso, el poema en prosa tiene que evitar las digresiones morales o de otro tipo. los desarrollos explicativos -todo lo que le llevaría a los otros géneros de la prosa, todo lo que afectaría a su unidad, a su densidad-. Precisamente porque su fuerza poética no viene de una encantación medida, sino de una síntesis iluminadora, le podemos aplicar en todo su rigor la famosa declaracjón de Poe: "Un poema largo no existe; lo que entendemos por un poema largo es una perfecta contradicción de términos". Lo hemos notado ya y lo podemos plantear como principio, el poema en prosa moderno es siempre breve".

11 "la "poesín real" consiste intrínsecamente en una descarga de corta duración. En algunos casos (como en el imaginismo, en la obra de Reverty. en el surrealismo) la poesía se convierte en sinónimo de las imágenes, entendidas como vehículos de revelación analógicas que se produce en un instante". 
Un texto extenso y continuo podrá ser poético, pero no se constituirá como poema, La brevedad no significa que necesariamente un texto breve sea un poema en prosa; de hecho John Simon (1965: 664) afirma que algunos poemas en prosa de Baudelaire son poco poéticos. Resulta, en cualquier caso, muy difícil establecer criterios de exclusión de textos breves en prosa, incluidos en colecciones poéticas, atendiendo al posible grado de "prosaísmo" de su lenguaje o al carácter anecdótico y narrativo del motivo literario.

Para Luis Ignacio Helguera, autor de una interesante antología del poema en prosa en México (1993: 14), el criterio de la brevedad, frecuentemente asociado a la definición del poema en prosa, es cuestionable. Sin embargo, el ejemplo que aduce como "poema en prosa extenso", Los cantos de Maldoror de Lautréamont, es igualmente discutible, ptes caben dos posturas, o bien considerarlo como poema en prosa extenso, o bien como un conjunto de poemas en prosa.

Al respecto, y a propósito de las observaciones de Butor ${ }^{12}$ sobre la posible concepción de los Petits poèmes en prose de Baudelaire como capítulos de una hipotética novela, idea que justificaría su afirmación de que la poesía puede lograrse y modularse mediante una estructura literaria tan amplia como una novela, Michel Beaujour (1983: 25) se pregunta muy atinadamente si is it acceptable to suggest that a long "spatial" or "topographical" work is indeed a macro-"prose poem"? Is not the lyrical emphasis on shortness and discreteness in compatible with the structural poetics implicit in Butor's conception of the "poetics novel" and, by extension, "the long poetic work in

Sobre la obra que suscita esta controversia, coincidimos con Beaujour (1983: 46) en que Le Spleen de Paris no es un poema largo, sino una colección de poemas que pueden publicarse y leerse por partes, lo que no impide que puedan estar vinculados entre sí por algún tipo de similitud temática, genérica o modal. A Los Cantos de Maldoror se le puede aplicar, creo, la misma solución. En español se pueden aducir también algunos casos similares de obras en las que podrían planteurse dudas genéricas razonables. Pueden citarse, entre otros, los ejemplos de Pasión de la tierra de Vicente Aleixandre, Ocnos de Luis Cernuda, y los casos más especiales de Crimen de Agustín Espinosa, y Platero y yo y "Espacio" de Juan Ramón Jiménez. De todos ellos, y con la excepción del poema "Espacio", que requiere un tratamiento especial dadas sus peculiares características, se puede concluir que son conjuntos de poemas en prosa que, en algún caso,

${ }^{12}$ Michel Butor, "Le Roman el In pocsie". Repertoire $/$, Paris, Éditions de Minuit, 1964, pp. 24-25; apud Michel Beaujour (1983: 25).

11 " ¿es aceptable sugerir que una obra larga, "espacial" o "topograíica", es en realidad un macro-"poema en prosa"? ¿No es el énfasis lírico sobre la brevedad y la discreción, incompatible con la poesia estructural implícita en el concepto de Butor de "novela poética" y, por extensión, "la obra poética larga en prosa"?" 
como Platero y yo y Crimen, pueden, a su vez, configurar otras entidades literarias más generales.

Esta última cuestión nos lleva a otra idea sobre la que también ha habido, en principio, bastante coincidencia. Nos referimos al eriterio de creación voluntaria o intencionalidad del autor. Maurice Chapelan ${ }^{14}$ ya señalaba en su antologíu que sólo se pueden admitir bajo el título de poemas en prosa aquellos textos cuyos autores indicaron de alguna manera que querian serlo. Suzanne Bernard (1959: 12 y ss.) destaca la importancia que esta idea, pues no sólo permite eliminar muchos poemas en prosa "involuntarios", sino que ayuda a hacerse desde el principio una idea más justa del problema del poema en prosa. Para Bernard, el poema en prosa supone una voluntad consciente de organización de la materia en poema, lo que significa que ha habido un proceso previo de rellexión y búsqueda de nuevas fórmulas poéticas. Luis Cernuda (1959: 257) alirma al respecto que "no parece posible hablar de poesía en prosa hasta que su autor no nos dé indicio suficiente de que intentaba escribirla".

El criterio de la intención del autor puede plantearnos algunos problemas. No suele ser habitual que un autor manifieste explícitamente su propósito de componer poemas en prosa; sólo en casos muy concretos lo indica en el título o subtítulo, o en otros lugares como prólogos, introducciones, poéticas, etc.; por lo tanto hemos de admítir que con bastante frecuencia lo que existe es una intencionalidad implícita que se evidenciaria, sobre todo, de dos maneras: una, la presencia de textos en prosa insertos en poemarios en verso; y otra, la existencia de textos en prosa breves y de tono lírico de autores cuya producción sea íntegramente poética.

Pero ¿a qué conclusión hemos de llegar ante textos en los que no existan elementos o indicios suficientes que denoten una propensión clara hacia la composición de poemas en prosa? ¿Cabria hablar, en este caso, de intencionalidad implícita, pero ocasional? Nos referimos concretamente a autores cuya producción es casi exclusivamente novelesca, como es el caso de Pío Baroja en su Fantasias vascas, en donde hay composiciones -"Elogio sentimental del acordeón" y "Elogio de los viejos caballos del tiovivo", insertas en Paradox rey-, que, como señala Aullón de Haro (1979: 129), poseen "motivo, tratamiento e intensidad propios del poema"; o en $L a$ Voluntad de Azorín, en la que el mismo Aullón observa que "muchos de los capitulos son susceptibles de desarticulación. pudiéndose proponer parte de ellos, de manera fragmentaria, como un conjunto de poemas en prosa descriptivos". Gil de Biedma (1977: XI y XII) indica que en otros títulos del mismo autor -Castilla, Una hora de España, Pueblo, Doña Inés y Félix Vargas- podemos encontrar "secuencias de poema en prosa". No parece que en estos casos sea coherente y aceptable la aplicación de este criterio.

14 en "Introducción" a Anthologie du poème en prose, Julliard, 1946, p. XVI. Cito de Suzunne Bernard (1959: 13). 
puesto que sería más bien el lector, o mejor aún, el critico quien en definitiva adjudique al autor una posible intencionalidad, y estariamos situándonos, por tanto, en la órbita del receptor, no del autor ni del texto.

Por otro lado, también nos podemos encontrar con textos cuyo autor califica de poema en prosa, pero que no se ajustan por su extensión a los límites del poema en prosa, como, por ejemplo, "Temblor de cielo" de Vicente Huidobro, que posee unas treinta páginas, o "Espacio", de Juan Ramón Jiménez, poema de extensión y tono muy similares.

En cualquier caso, no debemos olvidar que la precisa determinación genérica de cualquier objeto artístico depende en gran medida de la experiencia en su lectura por parte del lector, en el desciframiento e identificación de una serie de características conocidas como tales por el lector. Carlos Bouson̄o (1970) plantea la posible existencia de unas "leyes" de la poesía, y del arte en general, que pueden reducirse a dos aserciones. La primera, que llama "ley de la individualización", responde a la necesidad de que la significación que el poeta ofrece se nos aparezca como "individualizada", es decir, que produzca "en el lector la impresión de que se individualiza, pese a que el contenido poemático, tras la manipulación retórica del poeta, continúe ostentando un resto de inevitable generalización". La segunda ley es la denominada del "asentimiento" o "aquiescencia", y se manifiesta cuando el contenido psíquico de, por ejemplo, un poema lírico, que se ha individualizado, o que nos da la impresión de haberlo hecho, a través de procedimientos retóricos, es asentido como tal y "legítimamente nacido en el poeta o personaje poemático que figura ser el poeta". Bousoño llega a la conclusión de que cada uno de los géneros literarios es un procedimiento que, sin saberlo, utiliza el escritor para provocar en los lectores el asentimiento al contenido de la obra. Maurice Chapelan decia en 1946, en la citada "introducción" a su antología, que el poema en prosa es un género sobre el que ningún teórico todavia ha tratado de promulgar leyes, por lo que la única prueba que demostraría que un poema en prosa es verdaderamente un poema, sólo puede aportarla el consentimiento de la sensibilidad de cada lector.

Este principio supone que el lector, como añade Bousoño (1970), posee una idea bastante precisa de lo que es cada uno de esos moldes literarios, idea que procede de ciertas convicciones nuestras o elementos cosmovisionarios, y como resulta que esas creencias varian o pueden variar con el tiempo, variarán en idéntica dirección nuestras ideas sobre los géneros y. por tanto, nuestras exigencias con respecto a éstos, lo que, en suma, ha de repercutir, sin duda, en el asentimiento que les otorguemos. Pero en el caso del poema en prosa, el lector o el crítico no suelen tener una idea precisa de cuál es exactamente el modelo, pues éste es, como ya hemos señalado, escaso, polimórfico y relativamente moderno, caracteres que no propician la aquiescencia del poema en prosa como un género definido. 


\section{MODALIDADES}

Desde sus origenes se atisban ya dos modos de conformarse la poesía en prosa. Suzanne Bernard (1959: 449 s5.) habla de dos tendencias divergentes que van a orientar la materia verbal, engendrando dos fórmulas artísticas opuestas; el poema "formal" y el poema "iluminación".

Ambas modalidades intentan responder a la necesidad de "ramener au "présent éternel" du poème l'écoulement temporel de l'écriture linéaire"15. El poema "formal" o "cíclico" lo hará por medio de estructuras y formas rítmicas regulares basadas en la repetición y la variación. El precursor de esta modalidad, más narrativa, fue el poeta francés Paul Fort (1872-1960), quien en sus Ballades françaises, publicadas en treinta volúmenes a partir de 1897, lleva a cabo una forma híbrida de expresión, consistente en poner en prosa rítmica textos muy breves a partir de versos anisosilábicos que conservan la sonoridad de la rima.

El poema "iluminación", por el contrario, intenta alcanzar la atemporalidad a través de la iluminación intuitiva y sintética, es decir, "c'est à la fois le "temps réel". ici. qui sera réduit au minimum, le poème se présentant sous forme d"un "tout" très bref. destiné à produire sur le lecteur une impresión de choc, de secousse poétique immédiate et trés intense, comme le voulait E. Poe, et le "temps représenté", dont la figure sera non plus un déroulement en ligne droite ou en cercle fermé, mais un point lumineux, d'un éclat fulgurant et instantané ${ }^{m !}$.

Esta doble visión del poema en prosa responde a la idea de Bernard de encauzar la evolución del género en dos vias complementarias: una, la que representa el poema formal, que ella llama también "artístico", caracterizado por una organización rítmica y cíclica rigurosa, en la que prevalecen el orden y la máxima armonia; y otra, la que se desprende de los poemas anárquicos, cuya principio fundamental en el rechazo de todo orden buscando lo que llama la estética de la discontinuidad y de la permanente reivindicación de la individualidad.

La situación actual del poema en prosa no es tan simple. La evolución normal del género está marcada por una búsqueda constante de nuevos esquemas y moldes formales. En unos casos se quedan en meros experimentos y en otros abren nuevas posibilidades expresivas que terminan convirtiéndose en modelo. En el panorama del poema en prosa español son los casos de Juan Ramón Jiménez y de Luis Cernuda los que nos ofrecen un lineal".

is "encauzar al "presente eterno" del poema el hujo temporal de la escritura

16، "Es a la vez el "tiempo real", que aquí serí reducido al mínimo, y que se presenta en el poema bajo la forma de un "todo" muy breve, destinado a producir sobre el lector una impresión de choque, de sacudida poética inmediata y muy intensa, como quería E. Poe, y el "tiempo representado", cuya ligura no será ya un desarrollo en línea recta o en círculo cerrado, sino un punto luminoso, un destello fulgurante e instantáneo". 
muestrario más diverso de poemas en prosa. De su obra se extraen las Tórmulas más novedosas y que más han influido posteriormente.

El criterio de la extensión, unido al de la dependencia intertextual, son los aspectos más incontrovertibles, y en los que debe basarse cualquier intento clasificatorio, si no queremos caer en una casuística temática o referencial que no resolvería nada.

Desde esta perspectiva se pueden proponer las siguientes modalidades generales;

a) Poema en prosa "puro". Es el que se ajusta más estrictamente a las características generales del poema en prosa, como son la brevedad -entre media y tres páginas-, la unidad, la condensación expresiva y la intencionalidad, manifiesta o implícita, del autor.

b) Poema en prosa "discursivo". Sus principales características son su mayor extensión, que puede oscilar entre las cinco y treinta páginas, y el tono reflexivo, intimista y fluyente. Tiende a manifestarse en el uso de una prosa seguida sin divisiones en párrafos, como se ejemplifica en el poema "Espacio" de Juan Ramón Jiménez, y en "Retrato de Felicidad Panero" de Luis Rosales. En algunos casos se acerca y puede confundirse con el ensayo lírico y con algunas poéticas.

c) Poema en prosa "intertextual". Suele ajustarse a una extensión media ligeramente superior a la del poema en prosa puro. Su singularidad estriba en que son poemas que pueden estar integrados desde su génesis en una entidad literaria superior, pero que poseen la autonomia suficiente para poder ser considerados también como poemas independientes. Esta modalidad, que tiene su origen en Los cantos de Maldoror de Lautréamont, fue muy cultivada en Francia. En España, Platero y yo de Juan Ramón Jiménez y Crimen de Agustín Espinosa son dos claros ejemplos.

Estas tres variantes no pretenden reducir todo el abanico de posibilidades expresivas, sino establecer los marcos generales en los que la expresión poética en prosa puede conformarse. Dentro de las tres modalidades expuestas se pueden establecer, a su vez, diversos tipos, sobre todo en la modalidad de poema en prosa "puro", dependiendo, básicamente, de la materia temática y su particular tratamiento poético.

\section{BIBLIOGRAFIA}

AULLÓN DE HARO, Pedro, 1979. "Ensayo sobre la aparición y desarrollo del Poema en Prosa en la literatura española", Analecta Malacitana, v. II, "1", pp. 109-136.

BAUDELAIRE. Charles, 1954. "^ Arsène Houssaye”, prólogo a Le spleen de Paris. Petits poèmes en prose, en Oeuvres complétes, Llbraire Gallimard, Paris, 1954, pp. 281-2.

BEAUJOUR, Michel, 1983. "Short Epiphanies: Two Contextual Approches to the French Prose Poem", en Mary Ann CAWS Y Hermine RIFFATERRE (eds.), pp. 39-59. 
BERNARD, Suzanne, 1959. Le poème en prose de Baudelaire jusqu'à nos jours, Paris, Libraire Nizet.

BOUSOÑ̄o, Carlos 1970. "Significación de los géneros literarios", Insula, $\mathbf{n}^{\circ}$ 281, abril, pp. 1, 14 y 15.

CAWS, Mary Ann, 1983. (y Hermine RIFFATERRE) (eds.) The Prose Poem in France. Theory and Practice, New York, Columbia University Press.

" 1983a. "The Self-Defining Prose Poem: On Its Edge", en Mary Ann CAWS y Hermine RIFFATERRE (eds.), pp. 180-197.

CERNUDA, Luis, 1971. "Bécquer y el poema en prosa español" (1959), en Luis Cernuda, Poesía y literatura, t. II, Barcelona, Seix Barral (1" ed., 1964), pp. 257-266.

CHAPELAN, Maurice, 1946. Anthologie du poème en prose, Julliard.

COHEN, Jean, 1974. Estructura del lenguaje poético, Madrid, Gredos (1 ${ }^{\mathrm{a}}$ ed. fr., 1966).

CRESPO, Ángel, 1966. "Muestrario del poema en prosa brasileño", Revista de cultura brasileña, V. 18 (septiembre), pp. 225-258.

DIAZ-PLAJA, Guillermo, 1956. El poema en prosa en España. Estudio critico y antologia, Barcelona, Editorial Gustavo Gili, S.A.

GIL DE BIEDMA, Jaime. 1977. "Luis Cernuda y la expresión poćtica en prosa", prólogo a Luis Cernuda, Ocnos seguido de Variaciones sobre tema mexicano, Madrid, Taurus, pp.VII-XIX.

HELGUERA, Luis Ignacio, 1993. Antología del poema en prosa en México, México D.F., Fondo de Cultura Económica.

RIFFATERRE, Hermine, 1983a. Reading Constants: The Practice of the Prose Poem", en Mary Ann CAWS y Hermine RIFFATERRE (eds.). pp. 98-116.

RIFFATERRE, Michel, 1983. "On the Prose Poem's Formal Fentures", en Mary Ann CAWS y Hermine RIFFATERRE (eds.), pp. 117-132.

S. [Simon], J. [John], 1965. "Prose poem (poem in prose)", en Alex Preminger, Frank J. Warnke, and O. B. Hardison (eds.), Princeton Encyclopedia of Poetry and Poetics, Princeton, Princeton U.P., pp.: 664-9.

TODOROV, Tzvetan, 1983, "Poetry Without Verse", en Mary Ann CAWS y Hermine RIFFATERRE (eds.), pp. 60-78. 